В последнее время вопросам повышения эффективности государственного управления в сфере социально-экономического развития и обеспечения национальной безопасности Российской Федерации уделяется повышенное внимание. Журнал «Власть» статьей В.П. Назарова и Д.А. Афиногенова «Проблемы развития общей теории национальной безопасности в контексте корректировки Стратегии национальной безопасности Российской Федерации", опубликованной в № 1 за 2020 г., открыл дискуссию о необходимости преодоления дефицита стратегического мышления. В данном номере мы публикуем значимую статью В.П. Бауэра и В.В. Еремина, в которой речь идет о выстраивании системы стратегического планирования в РФ в условиях современных вызовов и рисков с учетом исторического и нынешнего опыта Франции и Китая.

БАУЭР Владимир Петрович - доктор экономических наук, доцент; директор Центра стратегического прогнозирования и планирования Института экономической политики и проблем экономической безопасности Финансового университета при Правительстве РФ (125009, Россия, г. Москва, ул. Тверская, 22Б, стр. 3; bvp09@таil.ru)

ЕРЕМИН Владимир Владимирович - кандидат экономических наук, ведущий научный сотрудник Центра мониторинга и оценки экономической безопасности Института экономической политики и проблем экономической безопасности Финансового университета при Правительстве РФ (125009, Россия, г. Москва, ул. Тверская, 22Б, стр. 3; villy.eremin@gmail.com)

\title{
ФРАНЦУЗСКИЙ И КИТАЙСКИЙ ОПЫТ ДЛЯ СОВЕРШЕНСТВОВАНИЯ РОССИЙСКОЙ СИСТЕМЫ СТРАТЕГИЧЕСКОГО ПЛАНИРОВАНИЯ
}

\begin{abstract}
Аннотация. Применение зарубежного опыта в целях совершенствования российской системы стратегического планирования позволит сэкономить время и ресурсы, т.к. задачи развития экономики Российской Федерации будут решаться не только за счет собственных разработок, но и за счет мирового опыта. Предлагаемое сочетание французского и китайского опыта основано на том, что обе эти страны в сложный период своего развития использовали директивное планирование, впоследствии переходя от него к индикативному, а затем - и к стратегическому, что и предлагается внедрить в текущих российских реалиях.
\end{abstract}

Ключевые слова: стратегическое планирование, национальная безопасность, Франция, Китай (КНР), директивное планирование, индикативное планирование

\section{Важность и сущность стратегического планирования в современных условиях}

Российская социально-экономическая система в последнее время сталкивается с достаточно серьезными трудностями, ставшими отголосками негативных событий, охвативших весь мир. Прежде всего, это пандемия коронавирусной инфекции и ее последствия для экономики и общества, а также распад сделки ОПЕК+, усиливший турбулентность на рынке нефти и, таким образом, также оказавший значительное негативное влияние на российскую экономику.

Наряду с этими факторами Всемирный банк относит к негативным факторам, угрожающим росту российской экономики, такие, как возможность дальнейшего усиления санкционного давления; конфликты в мировой экономике, приводящие к осложнению условий мировой торговли; финансовые 
потрясения в странах с формирующимся рынком и развивающимися экономиками и др. 1

Перечень основных внутренних факторов угрозы росту российской экономики сформирован экспертом экономического и социального развития России Натальей Зубаревич на выступлении в Совете Федерации. В этот перечень входят: старение населения и сокращение численности рабочей силы; неравенство социально-экономического развития регионов, которое, в свою очередь, вызывает достаточно сильную поляризацию инвестиций; снижение доходов населения ${ }^{2}$.

Реалии сегодняшнего дня ставят перед Россией сложнейшие проблемы и требуют опоры на стратегическое планирование при проведении государственной политики обеспечения национальной безопасности и устойчивого социальноэкономического развития [Назаров, Афиногенов 2020: 9]. В ситуации, когда экономика всего мира входит в стадию экономической рецессии, было бы излишне оптимистичным предполагать, что российская экономика избежит этой участи. Дополнительные внешние и внутренние угрозы российской экономике лишь усугубят эту ситуацию.

В таких условиях преодолеть как социальные, так и экономические трудности Российская Федерация сможет, используя в качестве основы для этого совокупность обоснованно составленных, эффективных планов действий по решению конкретных задач. Для того чтобы быть эффективным инструментом регулирования столь масштабных задач, эта совокупность планов должна включать в себя как долгосрочные, так и служащие их основой среднесрочные и краткосрочные планы, систему ресурсообеспечения и контроля за выполнением планов, своевременным и целевым расходованием средств. Основой этой совокупности должна быть система разноуровневых целей, достижение которых позволит решить стоящие перед РФ задачи по преодолению эпидемии и восстановлению экономики после ее завершения.

Фактически выше речь идет о системе стратегического планирования, которая позволит всем органам и службам РФ перейти от краткосрочного планирования, направленного на решение текущих задач, к долгосрочному целеполаганию и планированию [Букреев 2018: 88].

Такая система в РФ выстраивается и устойчиво развивается. Важными примерами этого являются изменения в российском законодательстве, происходящие в последние годы. Это и принятие в 2014 г. федерального закона № 172-Ф3 «О стратегическом планировании в Российской Федерации», и утвержденный Президентом в 2018 г. указ № 204 «О национальных целях и стратегических задачах развития Российской Федерации на период до 2024 года», а также принятое в этом же 2018 г. постановление Правительства РФ № 1288 «Об организации проектной деятельности в Правительстве Российской Федерации». Эти и многие другие нормативные правовые документы (включая государственные программы и национальные проекты) стали базой создания в РФ системы стратегического планирования, основанной на проектных принципах управления.

Негативные тренды развития мировой социально-экономической ситуации динамично нарастают [Рубини 2020], что ставит перед российской системой го-

\footnotetext{
${ }^{1}$ Всемирный банк прогнозирует сдержанные темпы роста в России и отмечает потенциал для увеличения занятости в формальном секторе. Доступ: https://www.vsemirnyjbank.org/ru/ news/press-release/2019/06/10/rer-41 (проверено 07.07.2020).

2 Сенаторам впервые зачитали правдивый доклад о положении России. Доступ: https://viralife.ru/senatoram-vpervye-zachitali-pravdivyy-doklad-o-polozhenii-rossii/?utm referrer=https\%3A\%2F\%2Fpulse.mail.ru\&utm_source=pulse_mail_ru (проверено 07.07.2020).
} 
сударственного управления в целом и системой стратегического планирования в частности вопросы, ответы на которые должны быть найдены в чрезвычайно сжатые сроки.

Один из выходов при формировании российской системы стратегического планирования в такой ситуации предусматривает как самостоятельный поиск решения поставленных задач, так и использование готовых вариантов решений из международного опыта стратегического планирования. Ниже авторы рассматривают основные направления использования такого опыта. Предлагается использовать сочетание опыта стратегического планирования Французской Республики и Китайской Народной Республики. Такое, на первый взгляд, нетривиальное сочетание основано на том, что обе эти страны в сложный период своего развития использовали директивное планирование, впоследствии переходя от него к индикативному планированию, а затем - и к стратегическому, что и предлагается повторить в текущих российских реалиях. Тем не менее опыт каждой из этих стран обладает своими особенностями, сочетание использования которых повысит эффективность применения этого опыта в России.

\section{Сущность российского стратегического планирования}

Определяя сущность стратегического планирования, нельзя не затронуть две ее основополагающие составляющие - нормативную, а также определение стратегического планирования с позиций менеджмента, в рамках которого оно и сформировалось. При этом подход к определению с позиций менеджмента следует скорректировать с учетом необходимости применения стратегического планирования в масштабах государства.

С позиций российского законодательства «стратегическое планирование деятельность участников стратегического планирования по целеполаганию, прогнозированию, планированию и программированию социально-экономического развития Российской Федерации, субъектов Российской Федерации и муниципальных образований, отраслей экономики и сфер государственного и муниципального управления, обеспечения национальной безопасности Российской Федерации, направленная на решение задач устойчивого социально-экономического развития Российской Федерации, субъектов Российской Федерации и муниципальных образований и обеспечение национальной безопасности Российской Федерации» ${ }^{1}$.

Кратким, но всеобъемлющим и включающим в себя подходы, заимствованные из менеджмента, является определение стратегического планирования, данное американскими учеными: стратегический план - это «детальный многосторонний комплексный план, необходимый для того, чтобы создать условия реализации миссии компании и достижение ее целей» [Казакова и др. 2016: 158]. Основной целью стратегического планирования является создание и реализация такого плана. При этом в представленном выше определении на уровне государства «миссия компании» заменяется на «национальные цели».

Необходимо обратить внимание на двойственность стратегического планирования: «стратегическое планирование можно представить, с одной стороны, как процесс (стратегический процесс), включающий совокупность действий, имеющих целью планирование одной либо нескольких стратегий (стратегический план), с другой - как научную дисциплину, которая создает способы, подходы, технологии планирования стратегии как специального вида плановых

1 Федеральный закон «О стратегическом планировании в Российской Федерации» от 28.06.2014 N 172-Ф3. Доступ: http://www.consultant.ru/document/cons_doc_LAW_164841/ (проверено 29.03.2020). 
документов, с помощью которых предприятие в будущем будет способно благополучно реализовывать свою предпринимательскую деятельность» [Бережная и др. 2019: 36].

На уровне государства «благополучная реализация своей предпринимательской деятельности» меняется на «эффективное и своевременное достижение национальных целей, реализацию стратегических планов, необходимых для этого достижения».

Исходя из того, что само понятие стратегического планирования сформировалось в недрах корпоративного менеджмента, совершенствуя российскую систему стратегического планирования, необходимо учитывать опыт, наработанный в этой сфере крупными корпорациями.

\section{Направления применения французского опыта стратегического планирования в российской практике}

В текущих сложных условиях развития российской экономики для РФ достаточно интересен опыт стратегического планирования Франции, накопленный ею после Второй мировой войны. Так, первые стратегические пятилетние планы развития французской экономики носили директивный характер, что обусловливалось сложностью экономической ситуации в разрушенной войной стране. Эти планы предполагали централизованное распределение ресурсов. На текущем этапе такой подход к стратегическому планированию является оптимальным для РФ и уже реализуется на практике через распределение финансовых ресурсов на реализацию государственных и федеральных программ, национальных проектов, ведомственных проектов и программ.

Дальнейшее развитие стратегического планирования во Франции с улучшением социально-экономической ситуации ознаменовалось переходом от дирижизма - политики директивного планирования - к политике индикативного планирования, при которой стратегические планы развития страны фиксируют лишь общие цели и приоритеты ее развития, при этом количественные показатели развития в этих стратегических планах играют меньшую роль, чем качественные. Французский опыт позволил обеспечить развитие индикативного планирования в Германии и Великобритании [Вертакова 2017: 37].

Анализируя французский опыт, мы делаем вывод, что основным направлением развития системы стратегического планирования РФ должно стать именно директивное планирование с определением сроков перехода к индикативному планированию, включая разработку комплекса соответствующих программ и мероприятий, позволяющих на практике реализовать этот план.

Чрезвычайно интересным с позиций применения в практике стратегического планирования РФ является французский опыт вовлечения экономических субъектов в процесс формирования стратегических планов и достижения запланированных показателей стратегического развития страны. Это участие является добровольным, основанным на системе финансовых льгот и стимулов. Французские предприятия сами заинтересованы в предоставлении своих статистических данных и прогнозов развития системе государственного стратегического планирования, т.к. предоставление этой информации является необходимым условием участия в конкурсах на получение государственных заказов [Бродская 2014: 10].

Развитие информационно-коммуникационных технологий позволяет вывести данный процесс в России на новый уровень качества, собирая необходимые для формирования стратегических прогнозов статистические данные в системе распределенных ситуационных центров развития в определенной степени автоматически [Авдеева и др. 2019: 260]. При этом участие в конкурсах на полу- 
чение государственных заказов будет (помимо предусмотренных наказаний за фальсификацию данных) стимулом для предоставления предприятиями достоверной информации о своей деятельности.

Также интересным для внедрения в практику российского стратегического планирования является французский опыт стимулирования участия предприятий в реализации стратегических планов, предусматривающий не директивные требования об участии со стороны государства предприятиям, а льготы, стимулирующие предприятия ради выгоды принимать участие в реализации директивных планов [Рассадина 2017: 45].

Подобную систему льгот и стимулов следует разработать и для российских предприятий. Затраты на ее разработку и реализацию окупятся за счет снижения затрат на систему вовлечения предприятий в процесс реализации стратегических планов государства и систему контроля за добросовестностью исполнения этими предприятиями государственных заказов. То есть, желая сохранить льготы, предприятие (его владельцы и менеджмент) будет само заинтересовано в участии в реализации стратегических планов государства, а значит и в своей добросовестной работе на этом направлении.

Чрезвычайно важным для российской системы стратегического планирования является французский опыт оценки и определенной верификации разработанных показателей стратегических планов французским научным сообществом. Без такой оценки эти показатели и планы не принимаются. Подобный подход позволит сделать показатели российских стратегических планов более обоснованными, что, в свою очередь, значительно повысит вероятность их достижения в указанный период времени.

Также чрезвычайно интересным для применения в российской практике стратегического планирования является французский опыт участия политических партий в процессе стратегического планирования. Партии в данном случае выступают своего рода экспертами. Возможно, что по определенным направлениям они предложат лучшие варианты стратегического развития страны, чем варианты, предлагаемые государственными органами стратегического планирования. Предлагается использовать стратегические планы, разрабатываемые партиями, в качестве дополнительного информационно-аналитического обеспечения разработки стратегических прогнозов и планов государственными органами стратегического планирования РФ. Для этого предлагается разработать общие требования к составу стратегических программ, предлагаемых партиями, регламенты и сроки их разработки [Трюэль, Рассадина 2017: 60].

Французский опыт стратегического планирования является опытом перехода от директивного к индикативному планированию, а далее - к стратегическому. Но в качестве первоначального (на данный момент) этапа развития системы стратегического планирования РФ предлагается именно директивное планирование, эффективные особенности которого, на наш взгляд, следует взять из китайского опыта планирования.

\section{Направления применения китайского опыта стратегического планирования в российской практике}

Анализируя китайский опыт стратегического планирования, следует особо отметить успехи китайской системы планирования в обеспечении сбалансированного развития, согласно которому эффективное стратегическое развитие страны заключается не только в достижении определенных темпов экономического роста, но и в сбалансированном развитии территорий страны и отраслей экономики [Петунин и др. 2019: 66]. Применение такого подхода в российских реалиях позволит в большей мере контролировать инфляцию, избегать кри- 
зисов, связанных с внутренней миграцией населения, и следующих за ними экологических проблем, избегать зависимости экономики страны от ограниченного набора отдельных отраслей.

В условиях определенного технологического отставания РФ в отдельных отраслях от ведущих индустриальных стран мира незаменимым является использование опыта Китайской Народной Республики по привлечению в целях стратегического развития экономики иностранного финансирования, и в особенности опыта по привлечению иностранных технологий [Хасбулатов и др. 2015].

Не менее интересным для применения в России, на наш взгляд, является и опыт Китая в стратегическом планировании по трем основным направлениям.

1. Программное планирование - применяется в рамках формирования комплексной стратегической программы развития КНР. Эта программа разбивается на пятилетние планы.

2. Планирование по основным объектам. Осуществляется по направлениям экономической деятельности, требующим государственного вмешательства в связи с низким уровнем эффективности рыночного регулирования экономики на этих направлениях (примером является китайская сеть высокоскоростных железных дорог).

3. Программы развития отдельных отраслей - за их формирование и реализацию отвечают соответствующие отраслевые ведомства КНР [Гиматдинов 2018: 209].

Полезным будет и применение в отечественных механизмах стратегического планирования китайской системы обратной связи, основанной на анкетировании респондентов.

В целом российское стратегическое планирование должно представлять собой просчитанную и обоснованную последовательность действий органов государственной власти, направленную на решение конкретной задачи, и в т.ч. на достижение неявной цели с учетом психологических склонностей объекта и других особенностей субъектов планируемой ситуации, т.е. их стратагему (в китайской терминологии) [Квинт 2014].

\section{Заключение}

Во всех рассмотренных системах стратегического планирования, а также в системах, анализ которых не вошел в статью (КНР, США, Франция, Германия), чрезвычайно важна роль специализированных аналитических центров и научноисследовательских институтов. На наш взгляд, этот опыт является ключевым для применения в российской системе стратегического планирования. РФ следует развивать сеть государственных и частных исследовательских центров для сбора, обработки и анализа информации, а также генерирования прогнозов и сводных отчетов, на основе которых будут определяться национальные цели и формироваться стратегические планы социально-экономического развития и обеспечения национальной безопасности РФ. Для этого необходима разработка методики оценки эффективности работы этих центров, во многом основанной на степени достоверности сделанных ими прогнозов [Беляева и др. 2016: 109].

Во всех промышленно развитых странах эти институты имеют высокий статус в структуре органов государственного управления, выражающийся в их прямом подчинении высшим должностным лицам исполнительной власти и в возможности координации действий других органов исполнительной власти при формировании экономической политики.

При формировании стратегических планов, в дальнейшем декомпозируемых на программы и проекты, необходимо учитывать генерируемые в процессе их 
реализации мультипликативные эффекты, смещающие траекторию стратегического развития страны [Еремин 2015; Сильвестров, Бауэр, Еремин 2018].

Также представляется необходимым использование опыта промышленно развитых государств, таких как США и Франция, по вовлечению частного бизнеса в процессы стратегического планирования развития экономики страны, т.к. исключительно государственные стратегические планы не будут реализованы, если они не совпадают со стратегическими планами ведущих бизнесменов относительно развития их бизнеса [Растянникова 2017: 709].

Сочетание российского и лучшего зарубежного опыта стратегического планирования сделает российскую систему стратегического планирования максимально гибкой [Калмыкова, Кабытов 2019: 114], позволяющей российской экономике эффективно преодолеть спад, вызванный действием негативных внешних факторов, в определенной степени усиливаемых внутренними проблемами в системе стратегического планирования [Городецкий 2019: 117; Кириченко, Гумеров 2019: 56].

Статья подготовлена по результатам исследований, выполненных засчет бюджетныхсредств по государственному заданию Финансовому университету при Правительстве Российской Федерации.

\section{Список литературы}

Авдеева 3.К., Райков А.Н., Бауэр В.П., Сильвестров С.Н., Славин Б.Б., Зацаринный А.А., Колин К.К., Лепский В.Е., Малинецкий Г.Г. 2019. Система распределенных ситуационных центров развития для устойчивого стратегического управления. - Рефлексивные процессы и управление: сборник материалов XII Международного научно-практического междисциплинарного симпозиума. Москва, 17-18 октября 2019 г. (отв. ред. В.Е. Лепский). М.: ООО «КогитоЦентр». С. 256-260.

Беляева Н.Ю., Ена О.В., Зайцев Д.Г., Чулок А.А. 2016. Оценка воздействия аналитических сообществ на изменения политико-управленческих решений. Вопросы государственного и муниципального управления. № 1. С. 103-128.

Бережная Л.Ю., Куценко Е.И., Рогочева Ю.С., Нагорная И.А. 2019. Стратегическое планирование: этапы и значение. - Фундаментальные и прикладные научные исследования: актуальные вопросы, достижения и инновации: сборник статей XIX Международной научно-практической конференции: в 2 ч. Пенза: МЦНС «Наука и Просвещение». С. 36-38.

Бродская И.А. 2014. Уроки французских индикативных планов (к разработке российской концепции макроэкономического планирования). - Экономические науки. № 7. С. 7-14.

Букреев В.В. 2018. Об актуальности планово-регулируемой экономики России в условиях ее цифровизации и глобализации. - Альтернативы. № 4. С. 87-112.

Вертакова Ю.В. 2017. Развитие системы индикативного и стратегического планирования при реализации государственной экономической политики на всех уровнях управления. - Известия Юго-Западного государственного универcumema. Сер. Экономика. Социология. Менеджмент. Т. 7. № 4(25). С. 30-56.

Гиматдинов Р.С. 2018. Развитие административного деления и стратегического планирования КНР. - Скиф. Вопросы студенческой науки. № 12(28). С. 207-210.

Городецкий А.Е. 2019. Государственное стратегическое планирование: региональный опыт. - Экономическое возрождение России. № 2(60). С. 115-131.

Еремин В.В. 2015. Математический анализ мультипликатора автономных расходов в статистике и динамике: монография. Уфа: Аэтерна. 130 с. 
Казакова Н.А., Александрова А.В., Курашова С.А., Кондрашева Н.Н. 2016. Стратегический менеджмент: учебник. М.: НИЦ «ИНФРА-М». 320 с.

Калмыкова А.В., Кабытов П.П. 2019. «Гибкие» структуры государственного управления. - Журнал российского права. № 8. С. 107-120.

Квинт В.Л. 2014. Стратегирование в современном мире: монография. СПб: Изд-во Северо-Западного института управления РАНХиГС при Президенте РФ. 52 c.

Кириченко И.А., Гумеров Р.Р. 2019. Реализация национальных целей и стратегическое планирование: фактор управления рисками. - Российский экономический жмурнал. № 6. С. 52-62.

Назаров В.П., Афиногенов Д.А. 2020. Проблемы развития общей теории национальной безопасности в контексте корректировки Стратегии национальной безопасности Российской Федерации. - Власть. Т. 28. № 1. С. 9-19.

Петунин Е.И., Бичиев Р.К., Вафин И.С., Кудалов Н.А. 2019. Стратегическое региональное планирование Китая. - Московский экономический жмурнал. № 7.

Рассадина А.К. 2017. Опыт индикативного планирования во Франции в свете задачи структурной трансформации российской экономики. - Hаучные исследования экономического факультета МГУ. Т. 9. № 1. С. 37-48.

Растянникова Е.В. 2017. БРИКС: новый этап планирования - индикативные и стратегические планы. - Экономика и предпринимательство. № 1(78). С. 705-711.

Рубини Н. 2020. Белые лебеди 2020 года. - Project Syndicate. Доступ: https:// www.project-syndicate.org/commentary/white-swan-risks-2020-by-nourielroubini-2020-02/russian (проверено 07.07.2020).

Сильвестров С.Н., Бауэр В.П., Еремин В.В. 2018. Оценка зависимости мультипликатора инвестиций от изменения структуры экономики региона. Экономика региона. Т. 14. № 4. С. 1463-1476.

Трюэль Ж.-Л., Рассадина А.К. 2017. Опыт французского планирования в контексте задачи модернизации российской экономики. - Экономическое возрождение России. № 1. С. 51-62.

Хасбулатов Р.И., Авдокушин Е.Ф., Аксенов П.А. и др. 2019. Китай в мировой экономике и международном бизнесе: монография. М.: Изд-во РЭУ им. Г.В. Плеханова. 250 с.

BAUER Vladimir Petrovich, Dr.Sci. (Econ.), Associate Professor; Head of the Center for Strategic Forecasting and Planning, Institute of Economic Policy and Economic Security Problems, Financial University under the Government of the Russian Federation (bld. 3, 225 Tverskaya St, Moscow, Russia, 125009; bvp09@mail.ru)

EREMIN Vladimir Vladimirovich, Cand.Sci. (Econ.), Leading Research Associate of the Center for Monitoring and Evaluation of Economic Security, Institute of Economic Policy and Economic Security Problems, Financial University under the Government of the Russian Federation (bld. 3, 225 Tverskaya St, Moscow, Russia, 125009; villy.eremin@ gmail.com)

\section{FRENCH AND CHINESE EXPERIENCE FOR IMPROVING THE RUSSIAN STRATEGIC PLANNING SYSTEM}

\footnotetext{
Abstract. An effectively built strategic planning system is the basis that will allow the Russian economy to overcome the recession caused by the action of negative external factors, reinforced by internal problems. The application of foreign experience in order to improve the Russian strategic planning system will save time and resources by solving the problems of developing the economy of the Russian Federation not only due to the own developments, but also due to answers already existing in the world experience. The proposed combination of French and Chinese experience is suggested as both of
} 
these countries used directive planning in the difficult period of their development, subsequently moving from it to indicative planning, which is proposed to be repeated in the current Russian realities.

Keywords: strategic planning, national security, France, China (PRC), directive planning, indicative planning

САИДОВ Санжар Шавкатович - доктор политических наук (PhD), Узбекский государственный университет мировых языков (100138, Узбекистан, г. Ташкент, ул. Кичик Халка Йули, 21a; s.saidov. uz@gmail.com

\section{ПЯТЬ ПРОБЕЛОВ В ГОСУДАРСТВЕННОЙ КАДРОВОЙ ПОЛИТИКЕ УЗБЕКИСТАНА}

Аннотация. В данной научной статье анализируются особенности и проблемы государственной кадровой политики в Республике Узбекистан. Отмечаются пять пробелов в сфере подбора, перестановки и подготовки государственных служащих в Узбекистане.

Ключевые слова: государственная кадровая политика, административная реформа, “утечка мозгов", креативный класс

$\mathrm{B}$ современных общественно-политических условиях в узбекистанском обществе государственная кадровая политика становится все более важным фактором эффективного госуправления. Ее роль постоянно возрастает вместе с ростом влияния человеческого фактора на решение политических, социальных, экономических и других проблем. Для того чтобы государственная кадровая политика стала действенной и результативной, необходима ее оптимизация как социально-политического института.

После резких политических событий в Узбекистане осенью 2016 г. наряду с социальными, экономическими и политическими изменениями в общественной жизни произошли некоторые модификации в кадровой политике государства. В одном из первых выступлений президента Ш. Мирзиеева отмечалось, что кадровая политика государства находится в «катастрофическом» положении и нуждается в кардинальных реформах. Исходя из этого мы попытались проанализировать некоторые особенности и пробелы кадровой политики в Узбекистане.

1. Слабая нормативно-правовая база. В 2017 г. была принята Концепция административной реформы в Республике Узбекистан и дорожная карта по ее реализации. В концепции отмечается, что главная цель этих документов - создание системы государственного управления, отвечающей общемировым тенденциям нового развития и способной обеспечить полноценную реализацию намеченных реформ, регулировать отношения в области государственной службы, своевременно выявлять и эффективно решать проблемы общественно-политического и социально-экономического развития страны ${ }^{1}$.

Однако эти документы не создали единую систему подбора кадров в органах государственного и хозяйственного управления. В выборе и перестановке

${ }^{1}$ Концепция административной реформы в Республике Узбекистан. 08.09.2017. Доступ: http://lex.uz/acts/3331176 (проверено 25.07.2020). 